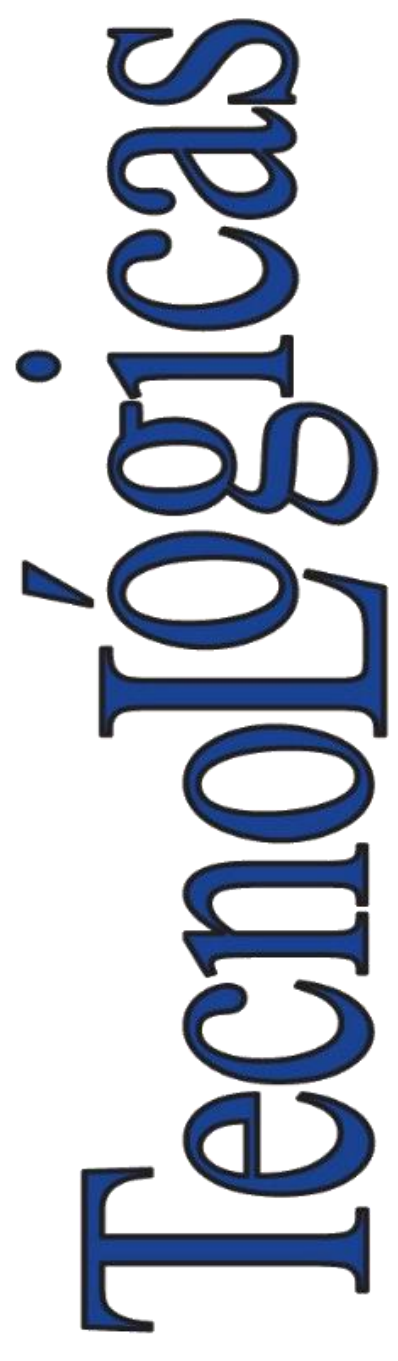

ISSN-p: 0123-7799 ISSN-e: 2256-5337

Vol. 24, nro. 52, e1962, 2021

Recibido: 13 abril 2021 Aceptado: 6 agosto 2021 Disponible: 26 agosto 2021

CInstituto Tecnológico Metropolitano

Este trabajo está licenciado bajo una Licencia Internacional

Creative Commons Atribución (CC BY-NC-SA)

\section{Avances en las investigaciones sobre la encapsulación mediante gelación iónica: una revisión sistemática}

\section{Advances in Research into Encapsulation through lonic Gelation: A Systematic Review}

\author{
(D) Nallely Ortiz-Romero ${ }^{1}$; \\ (D) - Luz Araceli Ochoa-Martínez ${ }^{2}$; \\ (D) Silvia Marina González-Herrera ${ }^{3}$; \\ (D) Olga Miriam Rutiaga-Quiñones ${ }^{4}$; \\ (D) José Alberto Gallegos-Infante ${ }^{5}$ \\ 1 Tecnológico Nacional de México/IT de Durango, Durango-México, \\ 11040768@itdurango.edu.mx \\ 2 Tecnológico Nacional de México/IT de Durango, Durango-México, \\ aochoa@itdurango.edu.mx \\ 3 Tecnológico Nacional de México/IT de Durango, Durango-México, \\ sgonzalez@itdurango.edu.mx \\ 4 Tecnológico Nacional de México/IT de Durango, Durango-México, \\ omrutiaga@itdurango.edu.mx \\ 5 Tecnológico Nacional de México/IT de Durango, Durango-México \\ jgallegos@itdurango.edu.mx
}

Cómo citar / How to cite

N. Ortiz-Romero; L. A. Ochoa-Martínez; S. M. González-Herrera; O. M. Rutiaga-Quiñones; J. A. Gallegos-Infante, "Avances en las investigaciones sobre la encapsulación mediante gelación iónica: una revisión sistemática", TecnoLógicas, vol. 24, nro. 52, e1962, 2021. https://doi.org/10.22430/22565337.1962 


\section{Resumen}

La encapsulación es una tecnología que proporciona barreras entre los compuestos de interés en un producto y el medio ambiente. Ella brinda una mejor estabilidad fisicoquímica durante el procesamiento y/o almacenamiento del producto, por lo tanto, ayuda a tener una menor degradación de los compuestos de interés, enmascara olores y sabores indeseables, controla la liberación del principio activo y puede incrementar su bioaccesibilidad y su biodisponibilidad. El objetivo de esta revisión fue recopilar y discutir la literatura reciente enfocada en investigaciones científicas sobre la encapsulación mediante gelación iónica de compuestos bioactivos, de microorganismos, de enzimas y su uso en diferentes aplicaciones de interés científico y/o industrial. La revisión bibliográfica se realizó en las principales bases de datos indexadas, utilizando descriptores como tamaño de cápsula, eficiencia de encapsulación, matrices mixtas, alginato de sodio y gelación iónica. De acuerdo con los resultados se observó que la utilización de este tipo de encapsulación presenta ventajas muy variables que se centran en la mejora de diversos factores como la biodisponibilidad de compuestos bioactivos, estabilidad de diferentes compuestos, características físicas, liberación del compuesto de interés y la protección contra efectos ambientales adversos. En conclusión, existe una amplia gama de aplicaciones que puede tener la metodología de gelación iónica para encapsular ingredientes alimenticios, microorganismos y fármacos, entre otros. Finalmente, el estudio pretende que esta revisión sea de utilidad en la dirección de investigaciones sobre gelación iónica, debido a la diversidad de aplicaciones abordadas durante la investigación.

\section{Palabras clave}

Alginato de sodio, compuestos bioactivos, gelación iónica, material de recubrimiento.

\section{Abstract}

Encapsulation, a technology that creates a barrier between a compound of interest and the environment, improves the physicochemical stability of products during processing and/or storage. Therefore, it helps to reduce the degradation of compounds of interest, masks undesirable odors and flavors, controls the release of the bioactive compound, and can increase its bioaccessibility and bioavailability. The objective of this review was to collect and discuss recent scientific literature about encapsulation by ionic gelation of bioactive compounds, microorganisms, and enzymes, as well as its use in different applications of scientific and/or industrial interest in several fields. A literature review was carried out in indexed databases using descriptors such as capsule size, encapsulation efficiency, mixture matrices, sodium alginate, and ionic gelation. The results show that using of this kind of encapsulation offers variable advantages regarding the bioavailability of bioactive compounds, the stability of different compounds, the improvement of physical characteristics, the release of compounds, and the protection against adverse environmental effects. In conclusion, the ionic gelation method can have a wide range of applications to encapsulate food ingredients, microorganisms, drugs, etc. This review can guide further research into ionic gelation because it examines the diversity of its applications.

\section{Keywords}

Sodium alginate, bioactive compounds, ionic gelation, wall material. 


\section{INTRODUCCIÓN}

La encapsulación es una alternativa útil para proteger compuestos de interés en productos alimenticios, farmacéuticos y cosméticos, entre otros. En el área de alimentos, un sistema eficiente de encapsulación debe permitir la incorporación de esos compuestos en matrices alimenticias, proporcionando alta estabilidad fisicoquímica y mínimo impacto en las propiedades organolépticas del producto [1]. La aplicación de este método proporciona ventajas como la mejora de la estabilidad oxidativa, reducción de la volatilidad de los compuestos aromáticos y la conservación frente a factores como oxígeno, humedad y luz [2], además de que permite enmascarar sabores desagradables. Existen diversos compuestos bioactivos que se encuentran en los alimentos en pequeñas cantidades, éstos son capaces de modular procesos metabólicos y tener como resultado una mejora en la salud [3]. Sin embargo, debido a su inestabilidad química y física, y por incompatibilidad entre el ingrediente activo y la matriz del alimento, la aplicación directa en alimentos es limitada. Por lo anterior, la incorporación de dichos compuestos bioactivos, en forma encapsulada, podría ser una eficiente alternativa de incorporación y/o conservación [4]. Por otro lado, los probióticos son microorganismos que administrados en cantidades adecuadas ejercen un efecto beneficioso a la salud, sin embargo, se ha observado que la influencia del estrés, la acidez gástrica, las sales biliares, la sensibilidad a enzimas, los niveles de oxígeno, de $\mathrm{pH}$ y la presencia de inhibidores interfieren en la viabilidad y sobrevivencia de los microorganismos, [5]. Por lo anterior, se han buscado metodologías para proporcionar una protección adecuada contra los diversos ambientes adversos y lograr así la estabilidad de los componentes de interés. Una de estas metodologías de encapsulación es mediante la gelación iónica, debido a su fácil preparación [6]. Las investigaciones en este tema han ido en aumento, se ha estudiado el efecto de diversas condiciones de proceso y diferentes materiales de recubrimiento sobre una amplia variedad de componentes, dando como resultado la versatilidad y utilidad de la gelación iónica en la conservación de productos. Con base en lo anterior, se consideró interesante elaborar una recopilación de resultados publicados, con la finalidad de facilitar perspectivas de investigación en un amplio campo. El objetivo de este trabajo fue revisar y discutir investigación reciente sobre el método de gelación iónica, para la cual se describe ampliamente en qué consiste la gelación iónica, los tipos de gelación, los materiales de recubrimiento comúnmente usados y su uso en matrices mixtas, así como su aplicación en la encapsulación de compuestos bioactivos, de microorganismos, de enzimas e igualmente su uso a nivel industrial para diferentes aplicaciones.

\section{MÉTODOS}

La revisión bibliográfica se inició en agosto de 2020, haciendo uso de las principales bases de datos, como SciELO, Springer, Elsevier, Science Direct, ResearchGate, Redalyc y Dialnet.

Los descriptores utilizados para la selección de artículos fueron tamaño de cápsula, eficiencia de encapsulación, matrices mixtas y utilización de alginato para la encapsulación por medio de gelación iónica. Para la revisión sistemática de la literatura, presentada en este artículo, se utilizó un enfoque de procesos investigativos de la encapsulación por gelación iónica. Se buscaron artículos originales y revisiones en inglés y español. 


\section{RESULTADOS}

Se revisaron un total de 84 artículos de investigaciones, de los cuales el $75 \%$ de los artículos son de los 5 años recientes. Las revistas de las cuales se obtuvo la mayor información son: Food Chemistry $11 \%$, Carbohydrate Polymers $6 \%$, Current Opinion in Biotechnology $6 \%$, Food Hydrocolloids $6 \%$, International Journal of Food $6 \%$ y Journal of Food Engineering $6 \%$.

Se encontró que la gelación iónica es ampliamente utilizada en diferentes áreas como la alimentaria, farmacéutica, cosmetológica y ambiental. En esta revisión, el $33 \%$ de los artículos están relacionados con la industria alimentaria, esto debido a su gran utilización en esta área.

\subsection{Gelación iónica}

La gelación iónica es una técnica de encapsulación que da como resultado cápsulas con un diámetro menor de $1000 \mu \mathrm{m}$, mediante el método de extrusión. Para llevar a cabo la gelación son necesarios materiales de recubrimiento, los cuales pueden ser gomas, carbohidratos, celulosas, lípidos, proteínas y materiales inorgánicos, y una solución reticulante, que, por lo general, son iones calcio (cloruro de calcio) [7], [8].

La gelación iónica consiste en producir pequeñas gotas de solución a partir de la mezcla del material de recubrimiento y el compuesto que se desea encapsular. El material de recubrimiento comúnmente usado es el alginato de sodio, debido a que es un polímero de fácil acceso, baja viscosidad y alta reactividad con los iones calcio. Esta solución se fuerza a través de boquillas generando gotas, y éstas caen en un baño de iones calcio formando así una cápsula de gel [9]. Este mecanismo se denomina de gelificación externa y es el más común y fácil para ambos tipos de compuestos, solubles e insolubles [10]. Se producen geles heterogéneos (Figura 1A), debido a que la gelificación en la superficie ocurre antes de la gelificación del núcleo, dando como resultado una superficie rígida y un núcleo blando [11].

Por otro lado, existe también el mecanismo denominado gelificación interna (Figura 1B), el cual consiste en la preparación de una solución de iones calcio y el compuesto de interés que se desea encapsular, esta mezcla se fuerza a través de una boquilla y se vierte en un baño de alginato de sodio. Para llevar a cabo la liberación de los iones calcio se acidifica el medio adicionando un ácido orgánico como el acético, adípico y la glucono $\delta$-lactona, se añade también un agente secuestrante, el cual se enlaza con el calcio libre retardando así el proceso de gelificación (Figura 1) [12], [13].

Entre las principales ventajas de la gelación iónica está que no emplea altas temperaturas ni disolventes orgánicos. Por otro lado, si se usan materiales de recubrimiento de bajo peso molecular, el producto tiende a presentar una rápida liberación a través del gel, por lo que es necesario el uso de otras estrategias como la preparación de una emulsión, ya que se ha demostrado que a través de ésta se brinda una liberación lenta dentro del organismo, dando una mejor absorción del compuesto encapsulado. La gelación externa brinda tamaños de cápsulas más grandes (>2000 $\mu \mathrm{m})$ y una mejor eficiencia de encapsulación, por ello se utiliza para la encapsulación de aceites esenciales, compuestos bioactivos y extractos [14]-[16]. Por su parte, la gelación interna se emplea más frecuentemente para la encapsulación de microrganismos debido a que se obtiene un tamaño de cápsulas uniforme y una superficie lisa, mediante la cual es menos probable que se produzcan aglutinaciones y, por lo tanto, menos grietas o poros [17], [18]. 
A)

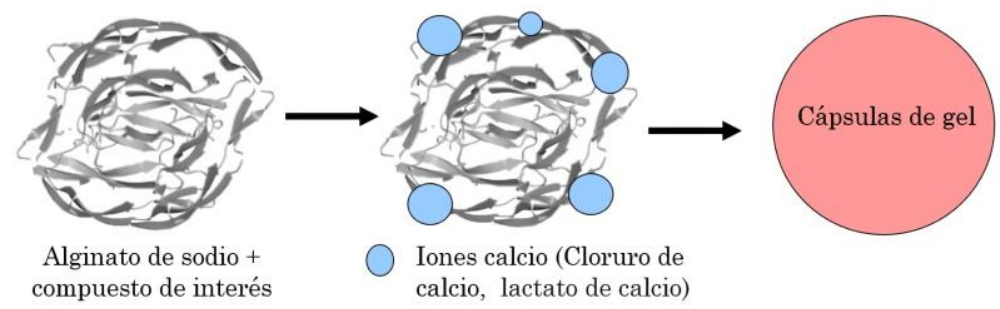

B)

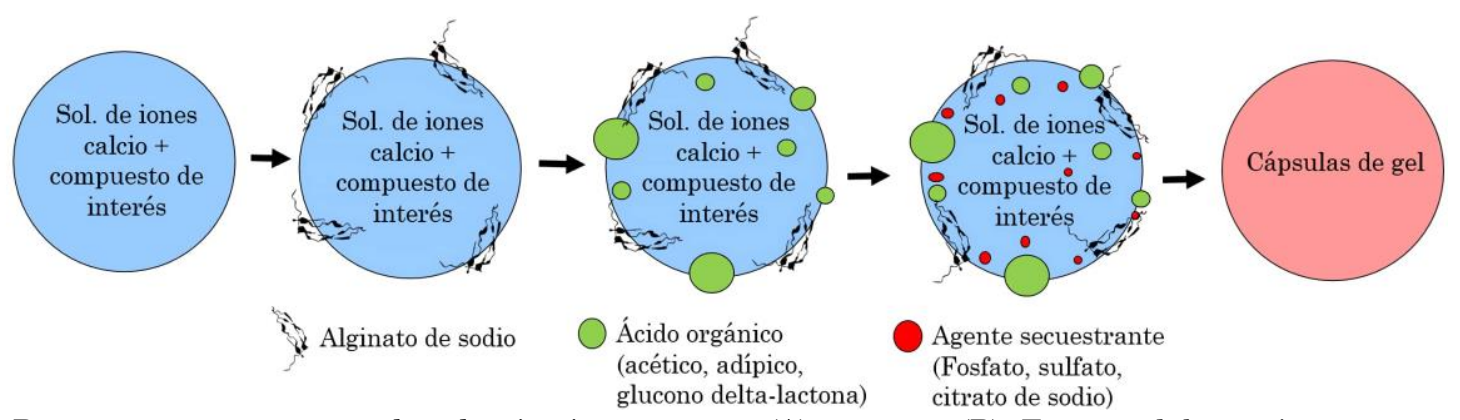

Figura 1. Diagrama representativo de gelación iónica externa (A) e interna (B). Fuente: elaboración propia.

En la investigación realizada por [19] utilizaron el proceso de gelación externa para encapsular la proteína de chícharo debido a su característica de tener un olor y sabor indeseables. En su investigación utilizaron alginato de sodio en diferentes concentraciones $(1 \%, 1.5 \%$ y $2 \%$ p/v) y encontraron que las cápsulas elaboradas con una concentración de $1 \%$ de alginato de sodio fueron más eficaces respecto a la conservación del contenido de proteína (30.26 \%) y al tamaño y estabilidad de las cápsulas. La concentración más alta de alginato de sodio (2.0\%) dio resultados positivos respecto a su morfología, debido a que se tenía mayor cantidad de alginato de sodio y se obtuvo una esfera uniforme. En [20] se evaluó la concentración de cloruro de calcio $(2 \%, 5 \%, 10 \%$ p/p) y utilizaron variación de tiempo (30 $\mathrm{min}, 45 \mathrm{~min}, 60 \mathrm{~min}$ ) para la encapsulación de aceite de toronja. Encontraron que el uso de $\mathrm{CaCl}_{2}$ a una concentración de $7.4 \%$ p/p y un tiempo de 58 minutos de reticulación tiene como resultado un rendimiento del $62 \%$, una eficiencia de encapsulación del $100 \%$ y una capacidad de carga de aceite de $10 \%$ p/p. Estos resultados pueden estar relacionados con un mayor tiempo de reticulación brindando un recubrimiento con mayor rigidez.

Se ha reportado el uso de la gelación interna para la encapsulación de probióticos como el caso de Bifidobacterium BB-12, la encapsulación ayudó a la protección de los probióticos y a una liberación controlada en condiciones gastrointestinales. La morfología de las cápsulas fue esférica, con superficie lisa y uniforme, y un tamaño de $(54.82 \pm 0.54) \mu \mathrm{m}$. Estas características se consideran favorables y proporcionan una opción de incorporación a los alimentos [21].

Bifidobacterium longum también se encapsuló utilizando alginato de sodio y quitosano como recubrimiento. Se elaboraron dos tipos de cápsulas, una con solo alginato y otra con una matriz mixta de alginato y quitosano, donde se observó que las cápsulas de la matriz mixta protegieron a Bifidobacterium longum del líquido gastrointestinal y de las altas temperaturas [18]. Lactobacillus delbrueckii es un probiótico, el cual, encapsulado con alginato de sodio (25\%) y gelana de alto acilo (75 \%), logró conservar el $50 \%$ de su viabilidad en jugos gástricos durante 240 minutos, reforzando así su viabilidad durante el paso a través del estómago. Este resultado es debido a que la goma gelana recubre los poros presentes en las cápsulas aumentando la eficiencia en la encapsulación e impidiendo la interacción entre el microorganismo y los jugos gástricos [22]. 
En [23] realizaron la microencapsulación de una emulsión de antocianinas de piel de uva mediante gelación interna y posteriormente la sometieron a un secado por aspersión y una liofilización. Los polvos secados por aspersión exhibieron una mayor eficiencia de encapsulación de antocianinas y tamaños de cápsulas más pequeños que los obtenidos por liofilización. En un estudio donde el objetivo fue maximizar la eficiencia de encapsulación mediante gelificación interna de una emulsión elaborada con $400 \mathrm{~mL}$ de aceite vegetal, $100 \mathrm{~mL}$ de tensoactivo y extracto de menta, utilizando como material de recubrimiento alginato de sodio al $0.5 \%, 0.05 \mathrm{M} \mathrm{CaCl}_{2}$, obtuvieron una eficiencia de encapsulación del $5.6 \%$ y un tamaño de cápsulas de $785 \mathrm{~nm}$. Los valores más altos del rendimiento de encapsulación se encontraron para mayores concentraciones de alginato, esto debido a la alta viscosidad del alginato que causa una mayor cohesión, lo que conduce a un atrapamiento de una mayor cantidad de material bioactivo [24].

En la Tabla 1 se presenta un resumen de trabajos de investigación con distintos mecanismos de gelación.

Tabla 1. Encapsulación por gelación iónica externa e interna de distintos compuestos de interés en diferentes matrices alimentarias. Fuente: Elaboración propia.

\begin{tabular}{|c|c|c|c|c|}
\hline $\begin{array}{l}\text { Compuesto de } \\
\text { interés }\end{array}$ & $\begin{array}{l}\text { Materiales de } \\
\text { encapsulación }\end{array}$ & $\begin{array}{l}\text { Tipo de } \\
\text { gelación }\end{array}$ & Resultado & Referencia \\
\hline $\begin{array}{l}\text { Extracto de } \\
\text { escamas de } \\
\text { cebolla }\end{array}$ & Alginato de sodio & Externa & $\begin{array}{l}\text { Las cápsulas elaboradas con el } \\
6 \% \text { de extracto mostraron la } \\
\text { máxima actividad antioxidante y } \\
\text { presentaron estabilidad frente al } \\
\text { fluido gástrico. }\end{array}$ & {$[25]$} \\
\hline $\begin{array}{l}\text { Extracto de } \\
\text { orujo de uva }\end{array}$ & Alginato de sodio & Externa & $\begin{array}{l}\text { La estabilidad a largo plazo de las } \\
\text { cápsulas ( } 6 \text { meses) presentó mayor } \\
\text { cantidad de polifenoles que en } \\
\text { estado libre. }\end{array}$ & {$[26]$} \\
\hline $\begin{array}{l}\text { Extracto de } \\
\text { orujo de uva }\end{array}$ & $\begin{array}{l}\text { Alginato de sodio y } \\
\text { quitosano }\end{array}$ & Externa & $\begin{array}{l}\text { La eficiencia de encapsulación } \\
\text { osciló entre } 55 \% \text { y } 79 \% \text {, la } \\
\text { eficiencia disminuyó al aumentar } \\
\text { el diámetro de las cápsulas. }\end{array}$ & {$[27]$} \\
\hline $\begin{array}{l}\text { Lactobacillus } \\
\text { acidophilus }\end{array}$ & $\begin{array}{l}\text { Pectina, inulina, salvado } \\
\text { y almidón }\end{array}$ & Interna & $\begin{array}{l}\text { Las cápsulas elaboradas con } \\
\text { salvado fueron las únicas en } \\
\text { mantener el microorganismo } \\
\text { viable durante } 120 \text { días. }\end{array}$ & {$[28]$} \\
\hline Espirulina & Alginato de sodio & $\begin{array}{l}\text { Interna y } \\
\text { externa }\end{array}$ & $\begin{array}{l}\text { La dureza de las cápsulas } \\
\text { elaboradas con gelación externa } \\
\text { fue tres veces más mayor que las } \\
\text { elaboradas con gelación interna, al } \\
\text { igual que el contenido de proteína. }\end{array}$ & {$[29]$} \\
\hline $\begin{array}{l}\text { Extracto de } \\
\text { diente de león }\end{array}$ & $\begin{array}{l}\text { Alginato de sodio, suero } \\
\text { de leche, pectina, } \\
\text { hidroxipropilmetilcelulosa } \\
\text { (HPMC) }\end{array}$ & Interna & $\begin{array}{l}\text { La matriz elaborada con alginato } \\
\text { de sodio y proteína de suero indicó } \\
\text { un óptimo sistema de entrega, } \\
\text { mientras que la matriz de alginato } \\
\text { y HPMC permitió una liberación } \\
\text { más prolongada en los fluidos } \\
\text { gastrointestinales. }\end{array}$ & {$[30]$} \\
\hline $\begin{array}{l}\text { Extracto de } \\
\text { cocoa }\end{array}$ & Alginato de sodio & $\begin{array}{l}\text { Interna y } \\
\text { externa }\end{array}$ & $\begin{array}{l}\text { Las cápsulas elaboradas por } \\
\text { gelación interna mostraron una } \\
\text { estructura interna más } \\
\text { homogénea y compacta. }\end{array}$ & {$[31]$} \\
\hline
\end{tabular}




\subsection{Materiales de recubrimiento en la encapsulación con gelación iónica}

La variedad de materiales que pueden emplearse para la microencapsulación se ha ampliado gradualmente en la medida en que surgen nuevos materiales de recubrimiento [32].

Las características para seleccionar el material de recubrimiento para la encapsulación son: [9], [32].

- La aplicación en la que se va a utilizar.

- El tipo de activo a utilizar.

- Capacidad de proteger el material encapsulado de la acción de factores externos.

- Habilidad de dispersarse con el material a encapsular.

- Capacidad de liberación del material encapsulado en condiciones específicas.

- Enmascara el sabor del encapsulado.

- Capacidad de cubrir y mantener dentro de su estructura al material encapsulado.

\subsubsection{Alginato de sodio}

Los alginatos son polisacáridos compuestos por unidades de ácido B-D-manurónico (M) y a-L-gulorónico $(\mathrm{G})$ que forman regiones de bloques $\mathrm{M}$ y bloques $\mathrm{G}$, así como bloques de secuencias alternas (MG) [33]. Las ventajas de este polisacárido es su producción debido a que se considera que es barata, ecológico, biocompatible y no tóxico [34]. Adicionalmente, el peso molecular del alginato de sodio $(216.12 \mathrm{~g} / \mathrm{mol})$ hace que se produzcan cápsulas de mayor dureza y tensión superficial [35].

El ácido algínico es soluble en agua y puede ser reticulado iónicamente con una solución de catión divalente no tóxico. La afinidad de un catión divalente es más fuerte para los isómeros $\mathrm{G}$ debido a la disposición esférica de los átomos, dos monómeros G forman una "caja de huevo" (Figura 2), el ion de calcio se asienta y retícula dos cadenas de polímero. Al hidrogel resultante comúnmente se le denomina alginato cálcico, y durante este proceso, la relación M/G afecta la capacidad de reticulación y, por lo tanto, las propiedades físicas del hidrogel [36].

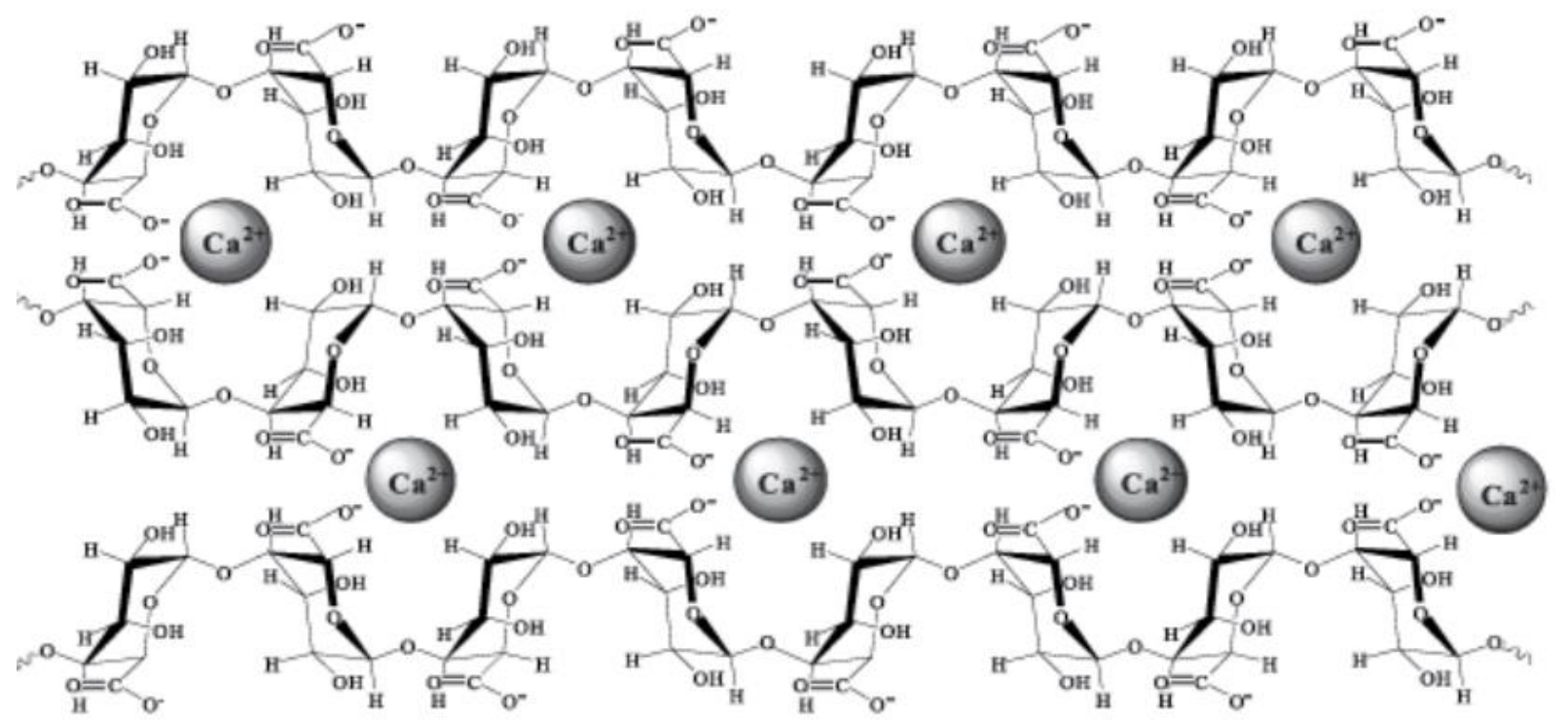

Figura 2. Modelo "caja de huevo" que describe la estructura del alginato. Fuente: [17]. 
El alginato de calcio es usado ampliamente en la industria farmacéutica como un elemento de recubrimiento en fármacos, ya que facilita la liberación controlada de sustancias activas, permitiendo la incorporación de varios ingredientes [37]. La encapsulación de doxorrubicina en nanocápsulas con alginato facilitaron la liberación controlada del fármaco, mejorando la eficiencia contra el carcinoma de Ehrlich [38]. Se encapsuló lovastatina utilizando como material de recubrimiento alginato y quitosano. Se obtuvieron nanocápsulas con un tamaño de $50 \mathrm{~nm}$ a $80 \mathrm{~nm}$, y se administraron a ratones para determinar su toxicidad. Se concluyó que las nanocápsulas son un portador seguro del fármaco e igualmente se puede aplicar para poder reducir el colesterol [39]. El diclofenaco sódico ha demostrado que es un irritante para el estómago por lo que se ha buscado una opción para un nuevo método de administración. Se encapsuló diclofenaco sódico utilizando como materiales de recubrimientos alginato de sodio (SA), óxido de zinc (ZnO NPs) y carboximetil quitosano (CMCS), dando como resultado una matriz mixta SA/CMCS-ZnO $(0.1 \mathrm{~g} / \mathrm{g})$ con una eficiencia de encapsulación de 82.32 y una carga de diclofenaco sódico de 7.56 \%. El fármaco presentó una liberación lenta, esto se atribuyó al aumento de la densidad de reticulación, lo cual se demostró por las pruebas in vitro [40].

Otra aplicación interesante del alginato de calcio es la encapsulación de bacterias nitrificantes las cuales se utilizan en el tratamiento de aguas residuales para eliminar nitrógeno amoniacal [41]. El alginato también tiene algunas limitaciones: no es compatible con metales pesados, ya que proporciona mala estabilidad; además, el alginato de sodio sin modificar presenta una pobre reactividad y es inestable bajo tratamiento térmico [37]. Estas limitaciones se pueden subsanar cambiando el alginato con otros biopolímeros para realizar una matriz mixta. Las anteriores aplicaciones de la metodología de gelación iónica demuestran lo versátil y útil que puede ser esta técnica en diversas áreas.

\subsubsection{Pectinas}

La pectina es un polisacárido no tóxico y económico que se extrae de la cáscara de los cítricos. Se ha utilizado como aditivo alimentario, ya sea como agente espesante o gelificante, y también para administración de fármacos en un sitio específico debido a la duración de contacto [42]. Tiene como componente común y principal una cadena lineal central constituida de unidades de ácido poli-a-D-galacturónico unidas por enlaces glucosídicos. Al utilizar las pectinas como material de recubrimiento, cuyo peso molecular es de $194.14 \mathrm{~g} / \mathrm{mol}$, se forman geles reversibles por su interacción con cationes divalentes [43].

El aceite de linaza es una fuente de ácidos grasos poliinsaturados, donde el $50 \%$ es ácido alfa-linolénico, por ende, es muy susceptible a la oxidación. Se encapsuló aceite de linaza por medio de gelación iónica utilizando pectina de bajo metoxilo al $3 \%$. Utilizaron, además, dos procesos en el secado de las cápsulas: secado a temperatura ambiente y mediante lecho fluidizado. Las cápsulas secadas en lecho fluidizado mostraron una menor oxidación en el aceite de linaza. Bajo condiciones de almacenamiento acelerado, las cápsulas presentaron mayor estabilidad cuando se secaron en lecho fluidizado que cuando se almacenó el aceite libre. Estos resultados demostraron la alta protección que otorga la encapsulación al aceite de linaza [44].

La clorhexidina (CX) es un antiséptico con una eficacia de amplio espectro. Este fármaco tiene una baja eficacia en presencia de saliva, por lo que se realizó una encapsulación por medio de gelación iónica externa con pectina como material de recubrimiento. Se obtuvo una eficiencia de encapsulación de $5.5 \%$, un rendimiento de encapsulación de $44 \%$, dando una liberación del fármaco de $7 \%$ después de 6 h [45].

En [46] encapsularon por medio de gelación iónica externa y secado por aspersión extracto de Hibiscus, utilizando como material de recubrimiento pectina. Los encapsulados se 
añadieron a un yogurt, y los resultados del estudio demostraron que cuando se usó la gelación iónica se obtuvo una mejor retención de antocianinas (48\%) y una diferencia de color baja ( $\Delta E=1.42$ ), lo cual indica un cambio mínimo en la coloración y, por lo tanto, mayor estabilidad en las antocianinas. Esta mayor estabilidad puede deberse a que, aunque las condiciones de secado por aspersión no son drásticas, si pudieron degradar las antocianinas, que son compuestos muy sensibles al calor. Siendo la gelación iónica una técnica más adecuada para compuestos sensibles al calor, se realizó un estudio en el cual se evaluaron dos tipos de pectina: pectina de manzana $(\mathrm{AP})$ y pectina de cítricos $(\mathrm{CP})$ para encapsular células C3A, esto para evaluar su capacidad de encapsulación celular. Los resultados que se obtuvieron no fueron muy diferentes entre sí, ya que las dos pectinas tienen parámetros moleculares similares, las cápsulas elaboradas con CP tuvieron una estructura rugosa en la superficie lo cual se atribuye a la proliferación de células, los dos tipos de pectina resultaron ideales para la encapsulación celular [47].

\subsubsection{Quitosano}

El quitosano es un polisacárido lineal no tóxico, biodegradable y biocompatible. Su estructura química se conforma en una cadena lineal de unidades N-acetil-D-glucosamina unidas por enlaces glicosídicos $\beta-1,4$ [48]. Es un biopolímero derivado de la quitina, es altamente aplicable en la industria farmacéutica y alimentaria debido a sus propiedades únicas, como no toxicidad, biocompatibilidad, biodegradabilidad y es extraíble de fuentes económicas [49].

Este polisacárido es utilizado en los procesos de encapsulación debido a su capacidad de reticulación iónica, la cual se produce cuando las cadenas de polímeros se unen mediante interacciones no covalentes que se presentan cuando se mezcla con moléculas de cargas opuestas, iones de carga opuesta se atraen electrostáticamente formando una matriz reticulada [50].

Se elaboraron nanocápsulas de quitosano como material de recubrimiento para encapsular biopéptidos. La caracterización fisicoquímica mostró un tamaño de cápsulas de $162.70 \mathrm{~nm}$, un potencial zeta de $+48.78 \mathrm{mV}$ y una eficiencia de encapsulación de $75.36 \%$. También se demostró que las nanocápsulas eran homogéneas y esféricas. El aumento de la concentración de quitosano provocó una disminución en el efecto de cizallamiento, lo que condujo a una formulación viscosa las cuales se caracterizan por cápsulas de gran tamaño y una alta eficiencia de encapsulación [51]. En el trabajo realizado por [52] realizaron la encapsulación por gelación iónica de palmitato de retinol, utilizando como material de recubrimiento quitosano, esto con el objetivo de usarlo como un nanosistema antioxidante. De acuerdo con los resultados, se obtuvo una eficiencia de encapsulación de $64 \%$, un diámetro de cápsulas de $350 \mathrm{~nm}$ que presentó distribuciones unimodales con una polidispersidad estrecha y un potencial zeta de $+30.6 \mathrm{mV}$ que es positivo debido a la naturaleza catiónica del quitosano.

El azafrán es una planta que tiene compuestos bioactivos como la picrocrocina, safranal y crocina. Estos compuestos sufren inestabilidad bajo condiciones ambientales. Por esto, se llevó a cabo la encapsulación del extracto de azafrán, utilizando como materiales de recubrimiento quitosano (CS) y goma arábiga (GA). Se formaron cápsulas esféricas y lisas, un tamaño de cápsulas de $295 \mathrm{~nm}$, un potencial zeta de $+50.5 \mathrm{mV}$ y una eficiencia de encapsulación de 52.34 \%. El estudio reveló que el aumento en CS y GA mejora la eficiencia de encapsulación, en cambio el aumento en el contenido de azafrán lo redujo, esto se debe a que a mayor contenido de materiales de pared la capa de pared es más gruesa y fuerte [49].

Se elaboraron nanocápsulas por gelación iónica utilizando como material de recubrimiento quitosano y tripolifosfato como agente reticulante, las cuales se cargaron con ácido salicílico 
con el objetivo de evaluar el uso de nanocápsulas de quitosano como un sistema de administración de fármacos. Los resultados que se obtuvieron fue una capacidad de carga de fármaco del $78 \%$ y una liberación del fármaco del $64 \%$ a las 72 h, dando así una liberación de fármaco más alto a su tercer día [53].

\subsubsection{Matrices mixtas}

La encapsulación a base de polímeros ha tenido un gran avance en los últimos años, se ha encontrado que la encapsulación elaborada a partir de un solo material de recubrimiento puede no proteger el compuesto encapsulado, por lo que se ha investigado la utilización de matrices mixtas para mejorar la conservación del compuesto. Estas matrices están hechas de dos o más materiales de recubrimiento, tienen muchas ventajas debido a que combinan los beneficios de cada material [54]. Por ejemplo, un estudio en el cual se realizó una encapsulación de aceite de sésamo con una matriz mixta de alginato de sodio y mucílago de nopal demostró que las cápsulas con matriz mixta tuvieron una mayor eficiencia de encapsulación $(75.44 \%)$ que las que tenían solamente alginato de sodio (63.48\%). Igualmente, se encontró una menor oxidación de aceite de sésamo en comparación con el que se encontraba libre y en cápsulas de alginato de sodio [55].

Se ha reportado el uso de proteína de soya, almidón de yuca y alginato de sodio para encapsular harina de zanahoria mediante la gelación iónica. La combinación que brindó una mejor protección ante la degradación del caroteno fue la de proteína de soya y almidón de yuca (50/50), presentando una vida útil de 106 días. De igual manera, con esta combinación, se incrementó la eficiencia de encapsulación, el rendimiento y el tamaño de la cápsula [56]. Se ha reportado que el uso de matrices mixtas conlleva principalmente a una mayor eficiencia en el proceso de encapsulación, probablemente debido a las características fisicoquímicas y funcionales de los materiales de recubrimiento, tal como solubilidad y capacidad de absorción de agua y aceite.

\subsection{Encapsulación de compuestos de interés}

\subsubsection{Compuestos bioactivos}

Los compuestos bioactivos son componentes esenciales y no esenciales que se producen en la naturaleza; se consideran que son aquellos metabolitos secundarios de origen vegetal que aportan un beneficio a la salud más allá de los considerados como nutrición básica [57].

Los compuestos bioactivos se pueden agrupar en terpenoides, compuestos fenólicos y compuestos azufrados. Generalmente estos compuestos se encuentran en alimentos, principalmente en frutas, verduras, nueces, aceites y granos integrales, entre otros [3]. Su uso se encuentra limitado debido a que son sensibles a las condiciones de procesamiento y almacenamiento por su baja estabilidad, solubilidad, sensibilidad a la luz, $\mathrm{pH}$ y poca biodisponibilidad [58]. Por ello, se han buscado alternativas que ofrezcan una protección de las condiciones externas a los compuestos bioactivos. Existe investigación que indica que la gelación iónica brinda protección a estos compuestos. Tal como lo estudiado por [59] en donde reportaron la retención de un $15 \%$ a un $60 \%$ de betacianinas y polifenoles en cápsulas de Ca(II)-alginato, componentes que fueron extraídos de residuos industriales de betabel. Los autores señalan la importancia de tomar en cuenta la presencia de extractos naturales, lo cual modifica la red del alginato, provocando así la variación en el rendimiento de la encapsulación. 
Estudios realizados para extractos de Hibiscus Sabdariffa L., conocida como flor de Jamaica, indican que con temperaturas bajas como $40{ }^{\circ} \mathrm{C}$ y tiempos cortos (30 minutos) se puede obtener una menor pérdida de antocianinas, y el uso de solvente para la extracción más concentrado brinda una mayor estabilidad ante su degradación [60]. En [61] reportaron que la pasteurización influye en la capacidad antioxidante del aguamiel de Agave americana L., ya que se detectó una disminución de betacaroteno y vitamina C., lo que refuerza la necesidad de optar por técnicas alternativas de conservación.

En [6] realizaron una evaluación de la estabilidad de jugo de naranja encapsulado mediante gelación iónica. Para la encapsulación se utilizó alginato de sodio y pectina de alto metoxilo. Se demostró que las cápsulas almacenadas a $4{ }^{\circ} \mathrm{C}$ obtuvieron parámetros de calidad aceptables comparadas con las almacenadas a temperatura ambiente. Uno de los parámetros evaluados fue el color, el cual permaneció estable durante 12 días de almacenamiento, las cápsulas mostraron una forma esférica, todo esto a un $\mathrm{pH}$ de 2.5, una concentración de alginato de sodio de $2 \%(\mathrm{p} / \mathrm{v})$ y pectina $2 \%(\mathrm{p} / \mathrm{v})$.

La microencapsulación de compuestos bioactivos ha tomado gran auge debido al impacto positivo que representan en la salud humana. La técnica de microencapsulación mediante secado por aspersión es la más usada para la conservación de estos componentes. A través de esta revisión es posible visualizar el potencial que tiene la gelación iónica como una alternativa de conservación para este tipo de compuestos.

\subsubsection{Microorganismos}

Santos \& Machado Se evaluaron cápsulas elaboradas por gelación externa las cuales contenían Saccharomyces boulardii una levadura probiótica que se utiliza en los tratamientos y prevención de enfermedades de intestino. Los materiales de recubrimiento utilizados fueron alginato de sodio y quitosano. Se observó que las cápsulas elaboradas con la matriz mixta de alginato y quitosano presentaron una resistencia a las condiciones gastrointestinales simuladas y una mayor concentración (9.25-8.82 log $\mathrm{CFU} \mathrm{g}^{-1}$ ), e igualmente tuvieron mayor resistencia a los factores ambientales [62].

El Lactobacillus acidophilus es un probiótico cuya viabilidad disminuye con la exposición del entorno como un pH bajo, enzimas y ácidos biliares. Los microorganismos se encapsularon utilizando una matriz mixta entre ácido fítico, quitosano y almidón. Las cápsulas mostraron una forma esférica uniforme y un tamaño de cápsula de $1.5 \mathrm{~mm}$, esto se debe a que una viscosidad alta brinda un aumento en el tamaño de cápsula. Las cápsulas elaboradas con ácido fítico y quitosano fueron las más estables para la protección del probiótico en $\mathrm{pH}=1.5$ y $\mathrm{pH}=2$ y la pérdida de este solo fue de $0.69 \log \mathrm{UFC}^{-1}$. En tamaños de cápsula menores de $100 \mu \mathrm{m}$ disminuye la tasa de supervivencia de probióticos, por lo que un tamaño mayor brinda un efecto protector [63].

Aspergillus Oryzae es un hongo que se utiliza para llevar a cabo las fermentaciones en la preparación de bebidas y panadería. Este fue sometido a una encapsulación por gelación iónica externa con alginato de sodio, quitosano y tripsina. Los resultados demostraron que la eficiencia de encapsulación fue mayor cuando la cantidad de alginato fue el doble que la del quitosano, la actividad enzimática resultó con un tiempo de conservación de dos semanas. La matriz presentó condiciones adecuadas para la carga y conservación de compuestos bioactivos [64].

Se realizó una emulsión de Lactobacillus con medio Man, Rogosa y Sharpe (MRS), la cual se encapsuló por medio de gelación interna y alginato de sodio. Se elaboraron dos tipos de cápsulas unas adicionadas con agua y otras sin ella. El rendimiento de encapsulación en las muestras sin agua fue más alto $(100.66 \%)$ y se obtuvo un tamaño de cápsula de $53.64 \mu \mathrm{m}$. 
Igualmente, estas muestras brindaron una mayor protección a las bacterias probióticas [65].

\subsection{Otras aplicaciones}

La encapsulación por gelación iónica tiene un gran aporte a la industria alimentaria como el enmascaramiento de color, sabor, conservación e incorporación de componentes.

El uso de edulcorante en la industria alimentaria ha ido en aumento, como es el caso de la fructosa, la cual se obtiene por medio de una extracción de almidón de maíz y la utilización de catalizadores y enzimas. Por esto hay estudios en los cuales se hace uso de la gelación iónica para la obtención de fructosa, esto a partir de la inmovilización de la inulinasa en alginato de sodio [66].

Bifidobacterium bifidum se encapsuló por medio de gelación iónica externa en una matriz de alginato de sodio y k-carragenina. Estas cápsulas se adicionaron a queso cheddar con la finalidad de determinar la viabilidad del probiótico. Se descubrió que en los dos quesos adicionados con Bifidobacterium bifidum, uno en forma libre y otro encapsulado, se afectaron las propiedades fisicoquímicas, microbiológicas y sensoriales del queso cheddar. El queso adicionado con el probiótico encapsulado presentó una mejor supervivencia comparado con las que se encontraban en estado libre, de igual manera que en las condiciones gastrointestinales [67].

Se han realizado estudios para la viabilidad de la encapsulación de hierro, ya que ayudaría a la prevención de la anemia. Las ventajas que se pueden encontrar en la encapsulación del hierro es una mejora en la biodisponibilidad, reduce alteraciones organolépticas de productos fortificados y disminuye los trastornos gastrointestinales del uso de suplementos [68].

En la industria farmacéutica, la gelación iónica tiene un gran aporte debido a que los polímeros y reactivos biocompatibles garantizan un preliminar de la formulación, que se confirma llevándolo a un experimento in vitro e in vivo; también permite estimar el comportamiento de dicha formulación a largo plazo [69].

La aplicación de fertilizantes se usa para la producción agrícola, éstos se pierden en el medio ambiente causando que no puedan ser absorbidos por los cultivos y provocando pérdidas en el sector agrícola. En la investigación realizada por [70] encapsularon el fertilizante nitrato de potasio utilizando una matriz mixta de quitosano y almidón de papa, mostrando un rendimiento de liberación de nitrato de potasio de $94.89 \%$ a las $2 \mathrm{~h}$ [70].

Pseudomonas putida, es una bacteria promotora del crecimiento de las plantas, las cuales se ven influenciadas por factores como la temperatura, la humedad, $\mathrm{pH}$ y la salinización del suelo. Se llevó a cabo una encapsulación de esta bacteria por gelación iónica externa. Las cápsulas se elaboraron con alginato de sodio $(1.5 \mathrm{~g})$, bentonita $(0.5 \mathrm{~g})$, suspensión bacteriana $\left(2 \mathrm{x} 10^{\wedge} 8 \mathrm{ufc} / \mathrm{mL}\right)$ y $\mathrm{CaCl}_{2}(2 \%)$. La encapsulación demostró una supervivencia mayor para las bacterias encapsuladas a comparación de las bacterias libres, las cápsulas presentaron un diámetro de $25 \mu \mathrm{m}$ a $100 \mu \mathrm{m}$ y una superficie rugosa. En la elaboración de cápsulas se tuvo una variación en la velocidad de agitación (900 rpm -1800 rpm), por lo que el recubrimiento y la velocidad de agitación afectaron significativamente el tamaño y la monodispersidad [71].

El alginato tiene propiedades biocompatibles y rentables, haciéndolo ampliamente utilizado en sectores del medio ambiente. Su principal uso es en la eliminación de contaminantes como metales pesados, antibióticos del agua y en aguas residuales [72].

En [73] elaboraron cápsulas de alginato y goethita, esto para absorber el arsénico de agua subterránea. Se demostró que las cápsulas son efectivas para la eliminación de arsénico con una sorción de $30.44 \mathrm{mgg}^{-1}$ [73]. La biosorción se utiliza para eliminar material coloidal durante el tratamiento de aguas. Se encapsuló el hongo Funalia Trogii para inmovilizarlo, 
utilizando alginato de sodio como material de recubrimiento; la capacidad máxima de biosorción fue de $102.3 \mathrm{mg}$, esto debido a que los iones metálicos electronegativos se sienten fuertemente atraídos por preparaciones fúngicas vivas e inactivas inmovilizadas [74].

Se realizó un estudio del rendimiento de adsorción de cápsulas compuestas de alginato de sodio y halloysita para la eliminación de $\mathrm{Pb}^{2+}$, obteniendo un resultado de capacidad de adsorción de $325 \mathrm{mg} / \mathrm{g}$, lo cual indica que la matriz mixta de alginato y halloysita contribuyen a la adsorción de $\mathrm{Pb}^{2+}$ por el intercambio iónico y fisisorción [75]. Se encontró que la inmovilización de $P$. laccase en cápsulas de alginato de calcio mejoró su estabilidad térmica y de almacenamiento. Las cápsulas se elaboraron a partir de alginato de sodio $(2 \% \mathrm{p} / \mathrm{v})$ y $\mathrm{CaCl}_{2}$ $(2 \% \mathrm{p} / \mathrm{v})$. El estudio demostró que la enzima inmovilizada tiene potencial para su aplicación en el tratamiento de colorantes en aguas residuales [76]. En la investigación llevada a cabo por [77] elaboraron dos tipos de cápsulas para eliminar el azul de metileno, debido a que se encuentra en aguas residuales y presentan un riesgo para la salud de todas las formas de vida. La primera donde el material de recubrimiento era carbón activado-alginato de sodio, y la segunda con carbón activado-bentonita-alginato. La cápsula con máxima adsorción fue la matriz mixta de carbón activado-bentonita-alginato $(756.97 \mathrm{mg})$. La combinación de los materiales de recubrimiento tiene una alta capacidad de adsorción debido a la gran superficie y la baja competencia entre las moléculas de tinte. La industria alimentaria produce toneladas de residuos orgánicos, los cuales provocan daños al medio ambiente, por lo tanto, se han buscado opciones para aprovechar tales residuos. En [78] utilizaron alginato de sodio para encapsular residuos de arándano, evaluaron el total de antocianinas (37.82 \pm 5.69$)$ y el contenido fenólico $(281.0 \pm 3.0)$ en el cual obtuvieron una retención fenólica de $(67.01 \pm$ $1.04) \%$, lo cual se debe a la viscosidad del alginato de sodio, ya que un aumento en la matriz tiene como consecuencia una encapsulación mayor de compuesto activo. En [79] obtuvieron extracto de Aronia melanocarpa L., la cual es un tipo de baya rica en polifenoles. Utilizaron una matriz mixta de alginato de sodio e inulina y como solución reticulante se utilizó $\mathrm{CaCl}_{2}$ (2 \%) y el extracto de Aronia. Probaron variación en los calibres de aguja (18, 20,22), contenido de inulina (0.5 \%) y tipo de alginato (baja viscosidad, viscosidad media). Se obtuvo una mejor liberación a partir de las cápsulas elaboradas con aguja de calibre 20, un alginato de viscosidad media y con un contenido de inulina del $5 \%$, las cuales contenían $0.24 \mathrm{mg}$ de GAE/g de polifenoles. Esto debido a que los polifenoles tienen una mayor afinidad por el alginato/inulina, ya que interaccionan los grupos polares de los polifenoles y los grupos hidroxilo de la inulina. Las micrografías electrónicas de barrido permitieron observar que la utilización de inulina favoreció las propiedades de las cápsulas.

En la encapsulación de extracto de maíz morado y de arándano por separado en una matriz compuesta por alginato y pectina, se encontró que la eficiencia de encapsulación del arándano con la matriz fue significativamente mayor a diferencia de la del maíz morado, esto debido a la compatibilidad de las estructuras. Durante el almacenamiento se reducían las pérdidas de antocianinas cuando se utilizaban bajas temperaturas [80].

En [81] elaboraron una emulsión con azafrán y achiote, la cual encapsularon utilizando quitosano y trifosfato de sodio como materiales de recubrimiento. El objetivo de este estudio fue evaluar la protección solar de la emulsión encapsulada, encontrando resultados de una protección mínima, ya que los valores variaron de 2.15 a 4.85 de factor de protección solar.

También se evaluó el pH durante el almacenamiento, el cual oscilaba en los rangos $5.44 \mathrm{a}$ 5.88, indicando así que es una emulsión viable para la utilización en la piel humana [81].

Las enzimas inmovilizadas por encapsulación muestran mejor estabilidad debido a que intensifican el control de su microambiente. Además, se ha demostrado que son catalíticamente activos en temperaturas más altas en disolventes orgánicos, así como también se separan fácilmente de la reacción sustrato-producto [82]. 
Se encapsuló lipasa de Penicillium crustosum, el cual se utiliza como biocatalizador para la producción de propionato de geranilo. Se utilizó alginato de sodio y cloruro de sodio como material de recubrimiento, las cápsulas tenían un diámetro de $0.5 \mathrm{~cm}$, las condiciones con las que se obtuvo la mayor concentración (50 \%) de la enzima fueron con una relación molar de 5:1 geranilo/ácido propiónico y $150 \mathrm{rpm}$ [83].

La enzima diamino oxidasa se encapsuló en una matriz mixta de almidón y alginato de sodio, presentando una menor porosidad, disminuyendo así el acceso del fluido gástrico al interior de la cápsula para no tener pérdida de la enzima; al igual, esta se encontraba activa mientras estaba encapsulada. La matriz brindó una protección a la enzima contra la degradación gastrointestinal [84].

Este apartado de la revisión presenta la versatilidad y utilidad de la gelación iónica para tratar aspectos importantes en las áreas de alimentos, residuos, aguas, farmacéutica y ambiental.

\section{CONCLUSIONES}

En la presente revisión se observó la amplia gama de aplicaciones que puede tener la metodología de gelación iónica para encapsular diversos compuestos, como ingredientes alimenticios, microorganismos, fármacos, etc. La utilización de este tipo de encapsulación presenta ventajas muy variables que se centran sobre la biodisponibilidad de compuestos bioactivos, estabilidad y durabilidad de diferentes compuestos, mejora en las características físicas y en la liberación del compuesto de interés, y, sobre todo, cómo brinda protección contra efectos ambientales adversos. Varios estudios han demostrado la utilidad del alginato de sodio como material de recubrimiento, y en combinación con otros materiales aquí expuestos, presenta grandes ventajas. En esta revisión se observó la gran importancia del uso de diferentes materiales de recubrimiento y su efecto en el tamaño de las cápsulas obtenidas, en la mejora en la estabilidad de los compuestos y en la mayor viabilidad de microorganismos, así como en mayor vida de anaquel. Lo anterior, con base en el tipo de compuesto que se desea encapsular y a los polímeros utilizados para la encapsulación. Respecto a su uso en el campo industrial, se puede decir que aún son necesarios más estudios debido a que la mayoría están realizados a escala de laboratorio. Se pretende que esta revisión sea de utilidad en la dirección de investigaciones sobre gelación iónica, lo anterior por la amplia gama de aplicaciones abordadas, lo cual puede incidir en el planteamiento de objetivos.

\section{AGRADECIMIENTOS}

La autora Ortiz-Romero agradece la beca otorgada por el Consejo Nacional de Ciencia y Tecnología (Conacyt) No. 747353 para realizar estudios de Doctorado en el Tecnológico Nacional de México/IT de Durango.

El artículo no contó con el apoyo económico de algún proyecto ni de alguna agencia financiadora pública o privada.

\section{CONFLICTOS DE INTERÉS}

Los autores declaran que no existe conflicto de intereses. 


\section{CONTRIBUCIÓN DE LOS AUTORES}

Nallely Ortiz-Romero participó en la conceptualización, alcance de la revisión y en la elaboración del primer borrador de la revisión.

Luz Araceli Ochoa-Martínez participó en la conceptualización y alcance de la revisión.

Silvia Marina González-Herrera y Olga Miriam Rutiaga-Quiñones participaron en la revisión y análisis de la información.

José Alberto Gallegos-Infante contribuyó en la edición del manuscrito.

\section{REFERENCIAS}

[1] F. Donsi; M. Annunziata; M. Sessa; G. Ferrari, "Nanoencapsulation of essential oils to enhance their antimicrobial activity in foods," LWT - Food Sci. Technol., vol. 44, no.9, pp. 1908-1914, Nov. 2011. https://doi.org/10.1016/j.lwt.2011.03.003

[2] A. Khezerlou; S. M. Jafari, "13- Nanoencapsulated bioactive components for active food packaging," in Handbook of Food Nanotechnology, Applications and Approaches, pp. 493-532, 2020. https://doi.org/10.1016/B978-0-12-815866-1.00013-3

[3] J. Gámez-Villazana, "Avances en la determinación de compuestos bioactivos en alimentos," Cienc. Tecnol. Agrollania, vol. 19, pp. 7-17, jun. 2020.

http://revistas.unellez.edu.ve/index.php/agrollania/article/view/960

[4] P. S. Anbinder; L. Deladino; A. S. Navarro; J. I. Amalvy; M. N. Martino, "Yerba Mate Extract Encapsulation with Alginate and Chitosan Systems: Interactions between Active Compound Encapsulation Polymers," J. Encapsulation Adsorpt. Sci., vol. 1, no. 4, pp. 80-87, Dec. 2011. http://dx.doi.org/10.4236/jeas.2011.14011

[5] H. Pérez-Leonard; G. Bueno García; M. A. Brizuela Herrada; K. Tortoló Cabañas; C. Gastón Peña, "Microencapsulación: una vía de protección para microorganismos probióticos," ICIDCA. Sobre los Deriv. la caña azúcar, vol. 47, no. 1, pp. 14-25, Jan. 2013. https://www.redalyc.org/articulo.oa?id=223126409003

[6] J. F. Castañón-Rodríguez; M. G. Soto-Gómez; R. M. Uresti-Marín, "Evaluación de la estabilidad de cápsulas de jugo de naranja obtenidas mediante gelificación iónica," CienciaUAT., vol. 14, no. 2, pp. 117-132, Jan. 2020. https://doi.org/10.29059/cienciauat.v14i2.1285

[7] P. Patil; D. Chavanke; M. Wagh, "A review on ionotropic gelation method: Novel approach for controlled gastroretentive gelispheres," Int. J. Pharm. Pharm. Sci., vol. 4, 2012. URL

[8] J. S. Patil; M. V. Kamalapur; S. C. Marapur; D. V. Kadam, "Ionotropic gelation and polyelectrolyte complexation: The novel techniques to design hydrogel particulate sustained, modulated drug delivery system: A review," Dig. J. Nanomater. Biostructures, vol. 5, no. 1, pp. 241-248, Mar. 2010. https://chalcogen.ro/241_Patil.pdf

[9] M. E. Ramírez Ortiz, Propiedades funcionales de hoy, Barcelona: Omnia Science, 2017. http://dx.doi.org/10.3926/oms.361

[10] N. Thi Thanh Uyen; Z. Ain Abdul Hamid; N. Xuan Thanh Tram; N. Ahmad, "Fabrication of alginate microspheres for drug delivery: a review," Int. J. Biol. Macromol., vol. 153, pp. 1035-1046, Jun. 2020. https://doi.org/10.1016/j.ijbiomac.2019.10.233

[11] S. H. Ching; N. Bansal; B. Bhandari, "Alginate gel particles-A review of production techniques and physical properties," Crit. Rev. Food Sci. Nutr., vol. 57, no. 6, pp. 1133-1152, Feb. 2017. https://doi.org/10.1080/10408398.2014.965773

[12] Q. Liu; A. M. Rauth; X. Yu Wu, "Immobilization and bioactivity of glucose oxidase in hydrogel microspheres formulated by an emulsification - internal gelation - adsorption - polyelectrolyte coating method," Int. J. Pharm., vol. 339, no. 1- 2, pp. 148-156, Jul. 2007. https://doi.org/10.1016/j.ijpharm.2007.02.027

[13] T. Helgerud; O. Gåserød; T. Fjæreide; P. O. Andersen; C. K. Larsen, "Alginates," in Food stabilizers, thickeners and gelling agents, A. Imeson, Ed. Oxford: United Kingdom: WileyBlackwell., 2010, pp. 50-72. https://doi.org/10.1002/9781444314724.ch4

[14] S. C. S. R. De Moura; C. L. Berling; S. P. M. Germer; I. D. Alvim; M. D. Hubinger, "Encapsulating anthocyanins from Hibiscus sabdariffa L. calyces by ionic gelation: Pigment stability during storage of microparticles," Food Chem., vol. 241, pp. 317-327, Feb. 2018.

https://doi.org/10.1016/j.foodchem.2017.08.095

[15] E. S. Kim; J. Lee; H. G. Lee, "Calcium-alginate microparticles for sustained release of catechin prepared via an emulsion gelation technique," Food Sci. Biotechnol., vol. 25, no. 5, pp. 1337-1343, Oct. 2016. https://doi.org/10.1007/s10068-016-0210-8 
[16] N. Colak et al., "Bog bilberry phenolics, antioxidant capacity and nutrient profile," Food Chem., vol. 201, pp. 339-349, Jun. 2016. https://doi.org/10.1016/j.foodchem.2016.01.062

[17] H. Yukio Kawaguti; H. Harumi Sato, "Produção de isomaltulose, um substituto da sacarose, utilizando glicosiltransferase microbiana, Isomaltulose production, a new sucrose substitute, using microbial glucosyl transferase," Quim. Nov., vol. 31, no. 1, pp. 134-143, 2008.

https://doi.org/10.1590/S0100-40422008000100025

[18] R. Ji et al., "Extending Viability of Bifidobacterium longum in Chitosan-Coated Alginate Microcapsules Using Emulsification and Internal Gelation Encapsulation Technology," Front. Microbiol., vol. 10, pp. 1-10, Jun. 2019. https://dx.doi.org/10.3389\%2Ffmicb.2019.01389

[19] C. Narin; U. Ertugrul; O. Tas; S. Sahin; M. H. Oztop, "Encapsulation of pea protein in an alginate matrix by cold set gelation method and use of the capsules in fruit juices," J. Food Sci., vol. 85, no. 10, pp. 34233431, Oct. 2020. https://doi.org/10.1111/1750-3841.15433

[20] L. M. Cáceres; G. A. Velasco; E. P. Dagnino; E. R. Chamorrro, "Microencapsulación de Aceite de Pomelo con Alginato de Sodio por Gelificación y Extrusión Iónica: Optimización y Modelado de la Reticulación y Estudio de la Cinética de Liberación Controlada," Rev. Tecnol. y Cienc., no. 39, pp. 41-61, Dec. 2020. http://dx.doi.org/10.33414/rtyc.39.41-61.2020

[21] A. Tasch Holkem et al., "Production of microcapsules containing Bifidobacterium BB-12 by emulsification/internal gelation," Food Sci. Technol., vol. 76, part B, pp. 216-221, Mar. 2017. https://doi.org/10.1016/j.lwt.2016.07.013

[22] R. E. González Cuello; J. Pérez Mendoza; L. B. Morón Alcázar, "Efecto de la Microencapsulación sobre la Viabilidad de Lactobacillus delbrueckii sometido a Jugos Gástricos Simulados,” Inf. Tecnológica, vol. 26, no. 5, pp. 11-16, 2015. http://dx.doi.org/10.4067/S0718-07642015000500003

[23] R. Zhang et al., "Microencapsulation of anthocyanins extracted from grape skin by emulsification/ internal gelation followed by spray/freeze-drying techniques: Characterization, stability and bioaccessibility," LWT - Food Sci. Technol., vol. 123, Apr. 2020. https://doi.org/10.1016/j.lwt.2020.109097

[24] S. Mokhtari; S. Mahdi Jafari; E. Assadpour, "Development of a nutraceutical nano-delivery system through emulsification/internal gelation of alginate," Food Chem., vol. 229, pp. 286-295, Aug. 2017. https://doi.org/10.1016/j.foodchem.2017.02.071

[25] S. R. Kanatt; S. Tari; S. P. Chawla, "Encapsulation of extract prepared from irradiated onion scales in alginate beads: a potential functional food ingredient," J. Food Meas. Charact., vol. 12, pp. 848-858, Dec. 2017. https://doi.org/10.1007/s11694-017-9699-7

[26] O. Aizpurua-Olaizola; P. Navarro; A. Vallejo; M. Olivares; N. Etxebarria; A. Usobiaga, "Microencapsulation and storage stability of polyphenols from Vitis vinifera grape wastes," Food Chem., vol. 190, pp. 614-621, Jan. 2016. https://doi.org/10.1016/j.foodchem.2015.05.117

[27] A. Moschona; M. Liakopoulou-Kyriakides, "Encapsulation of biological active phenolic compounds extracted from wine wastes in alginate-chitosan microbeads," J. Microencapsul., vol. 35, no. 3, pp. 229-240, Apr. 2018. https://doi.org/10.1080/02652048.2018.1462415

[28] G. C. Raddatz et al., "Influence of the prebiotics hi-maize, inulin and rice bran on the viability of pectin microparticles containing Lactobacillus acidophilus LA-5 obtained by internal gelation/emulsification," Powder Technol., vol. 362, pp. 409-415, Feb. 2020. https://doi.org/10.1016/j.powtec.2019.11.114

[29] D. Rajmohan; D. Bellmer, "Characterization of Spirulina-Alginate Beads Formed Using Ionic Gelation," Int. J. Food Sci., vol. 2019, Apr. 2019. https://doi.org/10.1155/2019/7101279

[30] A. Belščak-cvitanović et al., "Emulsion templated microencapsulation of dandelion (Taraxacum officinale L.) polyphenols and B-carotene by ionotropic gelation of alginate and pectin," Food Hydrocoll., vol. 57, pp. 139-152, Jun. 2016. https://doi.org/10.1016/j.foodhyd.2016.01.020

[31] B. Lupo; A. Maestro; J. M. Gutiérrez; C. González, "Characterization of alginate beads with encapsulated cocoa extract to prepare functional food: Comparison of two gelation mechanisms," Food Hydrocoll., vol. 49, pp. 25-34, Jul. 2015. https://doi.org/10.1016/j.foodhyd.2015.02.023

[32] C. de J. Hernández-Torres et al., "La microencapsulación de bioactivos para su aplicación en la industria" ICIDCA sobre los Derivados de la Caña de Azúcar, vol. 50, no. 1, pp. 12-19, Jan. 2016. https://www.redalyc.org/pdf/2231/223148420003.pdf

[33] S. Galus; A. Lenart, "Development and characterization of composite edible films based on sodium alginate and pectin," J. Food Eng., vol. 115, no. 4, pp. 459-465, Apr. 2013. https://doi.org/10.1016/j.jfoodeng.2012.03.006

[34] S. Sharma; P. Sanpui; A. Chattopadhyay; S. Sankar, "Fabrication of antibacterial silver nanoparticlesodium alginate-chitosan composite films," RSC Adv., vol. 2, no. 13, pp. 5837-5843, Apr. 2012. https://doi.org/10.1039/C2RA00006G

[35] D. L. Arvizu-Higuera; G. Hernández-Carmona; E. Rodríguez-Montesinos, "Parámetros que afectan la conversión del ácido algínico en alginato de sodio," Ciencias Mar., vol. 28, no. 1, Mar. 2002. https://www.redalyc.org/pdf/480/48028103.pdf 
[36] R. E. J. Forster et al., "Characterisation of physico-mechanical properties and degradation potential of calcium alginate beads for use in embolisation," Journal of Materials Science: Materials in Medicine, vol. 21, no. 7, pp. 2243-2251, Apr. 2010. https://doi.org/10.1007/s10856-010-4080-y

[37] R. Gheorghita Puscaselu; A. Lobiuc; M. Dimian; M. Covasa, "Alginate: From Food Industry to Biomedical Applications and Management of Metabolic Disorders," Polymers (Basel)., vol. 12, no. 10, Oct. 2020. https://dx.doi.org/10.3390\%2Fpolym 12102417

[38] N. Saad Elbialy; N. Mohamed, "Alginate-coated caseinate nanoparticles for doxorubicin delivery: Preparation, characterisation, and in vivo assessment," Int. J. Biol. Macromol., vol. 154, pp. 114-122, Jul. 2020. https://doi.org/10.1016/j.ijbiomac.2020.03.027

[39] H. Thai et al., "Characterization of chitosan/alginate/lovastatin nanoparticles and investigation of their toxic effects in vitro and in vivo," Sci. Rep., vol. 10, no. 909, Jan. 2020.

https://doi.org/10.1038/s41598-020-57666-8

[40] B. Niu et al., "In vitro and in vivo release of diclofenac sodium-loaded sodium aginate/carboxymethyl chitosan- ZnO hydrogel beads," Int. J. Biol. Macromol., vol. 141, pp. 1191-1198, Dec. 2019. https://doi.org/10.1016/j.ijbiomac.2019.09.059

[41] J. Sun; J. Liu; Y. Liu; Z. Li; J. Nan, "Optimization of Entrapping Conditions of Nitrifying Bacteria and Selection of Entrapping Agent," Procedia Environ. Sci., vol. 8, pp. 166-172, 2011. https://doi.org/10.1016/j.proenv.2011.10.027

[42] P. Sriamornsak; S. Sungthongjeen; S. Puttipipatkhachorn, "Use of pectin as a carrier for intragastric floating drug delivery: Carbonate salt contained beads," Carbohydr. Polym., vol. 67, no. 3, pp. 436-445, Feb. 2007. https://doi.org/10.1016/j.carbpol.2006.06.013

[43] V. K. Thakur; A. S. Singha, "Physicochemical and Mechanical Behavior of Cellulosic Pine Needle-Based Biocomposites," Int. J. Polym. Anal. Charact., vol. 16, no. 6, pp. 390-398, Aug. 2011. https://doi.org/10.1080/1023666X.2011.596303

[44] A. Menin et al., "Effects of microencapsulation by ionic gelation on the oxidative stability of flaxseed oil," Food Chem., vol. 269, pp. 293-299, Dec. 2018. https://doi.org/10.1016/j.foodchem.2018.06.144

[45] M. Lascol; S. Bourgeois; C. Barratier; P. Marote; P. Lanteri; C. Bordes, "Development of Pectin Microparticles by Using Ionotropic Gelation with Chlorhexidine as Cross-Linking Agent," Int. J. Pharm., vol. 542, no. 1-2, pp. 205-212, May. 2018. https://doi.org/10.1016/j.ijpharm.2018.03.011

[46] S. C. S. R. De Moura; G. N. Schettini; A. O. Garcia; D. A. Gallina; I. D. Alvim; M. D. Hubinger, "Stability of Hibiscus Extract Encapsulated by Ionic Gelation Incorporated in Yogurt," Food Bioprocess Technol., vol. 12, pp. 1500-1515, Jul. 2019. https://doi.org/10.1007/s11947-019-02308-9

[47] S. Zhao et al., "Study of chemical characteristics, gelation properties and biological application of calcium pectate prepared using apple or citrus pectin," Int. J. Biol. Macromol., vol. 109, pp. 108-187, Apr. 2018. https://doi.org/10.1016/j.ijbiomac.2017.12.082

[48] M. Rahat Hossain; A. K. Mallik; M. Mizanur Rahman, "Chapter 7 - Fundamentals of chitosan for biomedical applications," in Handbook of Chitin and Chitosan Chitin and Chitosan based Polymer Materials for Various Applications, Eds. Woodhead, 2017, pp. 3-30. https://doi.org/10.1016/B978-0-12-817966-6.00007-8

[49] H. Rajabi; S. Mahdi Jafari; G. Rajabzadeh; M. Sarfarazi; S. Sedaghati, "Chitosan-gum Arabic complex nanocarriers for encapsulation of saffron bioactive components," Colloids Surfaces: Physicochemical and Engineering Aspects, vol. 578, Oct. 2019. https://doi.org/10.1016/j.colsurfa.2019.123644

[50] S. K. H. Gulrez; S. Al-assaf; O. Phillips, "Hydrogels: Methods of Preparation, Characterisation and Applications," in Progress in Molecular and Environmental Bioengineering - From Analysis and Modeling to Technology Applications, InTech, 2011. http://dx.doi.org/10.5772/24553

[51] S. Muhammad Auwal; M. Zarei; C. Ping Tan; M. Basri; N. Saari, "Improved In Vivo Efficacy of AntiHypertensive Biopeptides Encapsulated in Chitosan Nanoparticles Fabricated by Ionotropic Gelation on Spontaneously Hypertensive Rats," Nanomaterials, vol. 7, no. 12, Dec. 2017.

https://dx.doi.org/10.3390\%2Fnano7120421

[52] M. Fernández-Gutiérrez; O. Bossio; L. G. Gómez-Mascaraque; B. Vázquez-Lasa; J. San Román, "Bioactive Chitosan Nanoparticles Loaded with Retinyl Palmitate: A Simple Route Using Ionotropic Gelation," Macromol. Chem. Phys., vol. 216, no. 12, pp. 1321-1332, Jun. 2015.

https://doi.org/10.1002/macp.201500034

[53] D. Ismik; D. Sezgin Mansuroglu; E. Bulus; Y. M. Sahin, "The Use of Chitosan Nanoparticles Obtained by Ionic Gelation Method as a Drug Delivery System,” J. Mater. Electron. devices, vol. 5, no. 1, pp. 6-11, Nov. 2020. http://dergi-fytronix.com/index.php/jmed/article/view/109

[54] Y. Luo; Q. Wang; Y. Zhang, "Biopolymer-based Nanotechnology Approaches to Deliver Bioactive Compounds for Food Applications: A Perspective on the Past, Present and Future," J. Agric. Food Chem., vol. 68, no. 46, pp. 12993-13000, Mar. 2020. https://doi.org/10.1021/acs.jafc.0c00277

[55] S. K. Velázquez-Gutierrez; E. Alpinazar-Reyes; J. Cruz-Olivares; J. F. Barrera-Pichardo; M. E. RodríguezHuezo; C. Pérez-Alonso, "Ionic gelation encapsulation of sesame oil with sodium alginate-nopal mucilage 
blends: Encapsulation efficiency and oxidative stability," Rev. Mex. Ing. Química, vol. 19, pp. 349-362, 2020. http://hdl.handle.net/20.500.11799/109009

[56] O. S. Kamaldeen; C. C. Ariahu; M. I. Yusufu, "Application of soy protein isolate and cassava starch-based film solutions as matrix for ionic encapsulation of carrot powders," J. Food Sci. Technol., vol. 57, pp. 41714181, Apr. 2020. https://doi.org/10.1007/s13197-020-04455-w

[57] F. H. Chalé; D. Betancur Ancona; M. R. Segura Campos, "Compuestos bioactivos de la dieta con potencial en la prevención de patologías relacionadas con sobrepeso y obesidad; péptidos biológicamente activos," Nutr. Hosp., vol. 29, no. 1, pp. 10-20, Sep. 2014. http://dx.doi.org/10.3305/nh.2014.29.1.6990

[58] M. R. Islam Shishir; L. Xie; C. Sun; X. Zheng; W. Chen, "Advances in micro and nano-encapsulation of bioactive compounds using biopolymer and lipid-based transporters," Trends food Sci. Technol., vol. 78, pp. 34-60, Aug. 2018. https://doi.org/10.1016/j.tifs.2018.05.018

[59] T. R. Aguirre Calvo; M. Perulline; P. R. Santagapita, "Encapsulation and betacyanins and polyphenols extracted from leaves and steams of beetroot in Ca(II)-alginate beads: A structural study," Journal of Food Engineering, vol. 235, pp. 32-40, Oct. 2018. https://doi.org/10.1016/j.jfoodeng.2018.04.015

[60] J. Villarroel; N. Sanabria; L. Pérez, "Compuestos bioactivos y degradación cinética de antocianinas en extractos de Hibiscus Sabdariffa L.,” Rev. Cienc. Tecnol. Agrollania, vol. 19, pp. 18-24, Jan. 2020.

[61] P. Chagua Rodríguez; R. J. Malpartida Yapias; A. Ruíz Rodríguez, "Tiempo de pasteurización y su respuesta en las características químicas y de capacidad antioxidante de aguamiel de Agave americana L.," Rev. Investig. Altoandinas, vol. 22, no. 1, pp. 45-57, Sep. 2020. http://dx.doi.org/10.18271/ria.2020.532

[62] M. A. S. Santos; M. T. C. Machado, "Coated alginate - chitosan particles to improve the stability of probiotic yeast,” Int. J. Food Sci. Technol., vol. 56, no. 5, pp. 2122-2131, May. 2020. https://doi.org/10.1111/ijfs.14829

[63] J. Un Kim; B. Kim; H. Muhammad Shahbaz; S. Hyun Lee; D. Park; J. Park, "Encapsulation of probiotic Lactobacillus acidophilus by ionic gelation with electrostatic extrusion for enhancement of survival under simulated gastric conditions and during refrigerated storage," Int. J. Food Sci. Technol., vol. 52, no. 2, pp. 519-530, Nov. 2016. https://doi.org/10.1111/ijfs.13308

[64] K. Ozaltin; P. S. Postnikov; M. E. Trusova; V. Sedlarik; A. Di Martino, "Polysaccharides based microspheres for multiple encapsulations and simultaneous release of proteases," Int. J. Biol. Macromol., vol. 132, pp. 24-31, Jul. 2019. https://doi.org/10.1016/j.ijbiomac.2019.03.189

[65] M. T. Sánchez; M. A. Ruíz; A. Lasserrot; M. Hormigo; M. E. Morales, "An improved ionic gelation method to encapsulate Lactobacillus spp. bacteria: Protection, survival and stability study," Food Hydrocoll., vol. 69, pp. 67-75, Aug. 2017. https://doi.org/10.1016/j.foodhyd.2017.01.019

[66] M. V. Lara Fiallos; T. Ayala Chamorro; E. González Suárez; A. Pérez Martínez, "Obtención de sirope de fructosa por encapsulación enzimática de inulinasa en alginato de sodio,” Rev. Cent. Azúcar, vol. 48, no. 1, pp. 117-126, Jan. 2021. http://centroazucar.uclv.edu.cu/index.php/centro_azucar/article/view/647

[67] M. Afzaal et al., "Encapsulation of Bifidobacterium bifidum by internal gelation method to access the viability in cheddar cheese and under simulated gastrointestinal conditions," Food Sci. Nutr., vol. 8, no. 6, pp. 2739-2747, Apr. 2020. https://doi.org/10.1002/fsn3.1562

[68] E. Durán; C. Villalobos; O. Churio; F. Pizarro; C. Valenzuela, "Encapsulación de hierro: Otra estrategia para la prevención o tratamiento de la anemia por deficiencia de hierro," Rev. Chil. Nutr., vol. 44, no. 3, pp. 234-243, jun. 2017. http://dx.doi.org/10.4067/s0717-75182017000300234

[69] S. Pedroso-Santana; N. Fleitas-Salazar, "Ionotropic gelation method in the synthesis of nanoparticles/microparticles for biomedical purposes," Polym. Int., vol. 69, no. 5, pp. 443-447, Jan. 2020. https://doi.org/10.1002/pi.5970

[70] J. J. Pérez Bravo; N. J. François, "Chitosan/Starch Matrices Prepared by Ionotropic Gelation: Rheological Characterization, Swelling Behavior and Potassium Nitrate Release Kinetics," J. Polym. Environ., vol. 28, pp. 2681-2690, Oct. 2020. https://doi.org/10.1007/s10924-020-01798-5

[71] X. Li; Z. Wu; Y. He; B. Ce Ye; J. Wang, "Preparation and characterization of monodisperse microcapsules with alginate and bentonite via external gelation technique encapsulating Pseudomonas putida Rs-198," J. Biomater. Sci. Polym. Ed., vol. 28, no. 14, pp. 1556-1571, Jun. 2017. https://doi.org/10.1080/09205063.2017.1335075

[72] B. Wang et al., "Alginate-based composites for environmental applications: a critical review," Crit. Rev. Environ. Sci. Technol., vol. 49, no. 4, pp. 318-356, Dec. 2018. https://doi.org/10.1080/10643389.2018.1547621

[73] H. Basu; R. K. Singhal; M. V. Pimple; A. V. R. Reddy, "Arsenic Removal from Groundwater by Goethite Impregnated Calcium Alginate Beads," Water, Air, Soil Pollut., vol. 226, Feb. 2015.

https://doi.org/10.1007/s11270-014-2251-z

[74] M. Y. Arıca; G. Bayramoglu; M. Yılmaz; S. Bektaş; O. Genc, "Biosorption of Hg2+, Cd2+, and Zn2+ by Caalginate and immobilized wood-rotting fungus Funalia trogii," J. Hazard. Mater., vol. 109, no. 1-3 pp. 191199, Jun. 2004. http://dx.doi.org/10.1016/j.jhazmat.2004.03.017

[75] C.S.C. Chiew et al., "Halloysite/alginate nanocomposite beads: Kinetics, equilibrium and mechanism for lead adsorption,” Appl. Clay Sci., vol. 119, part. 2, pp. 301-310, Jan. 2016. 
http://dx.doi.org/10.1016/j.clay.2015.10.032

[76] D. Daâssi; S. Rodríguez-Couto; M. Nasri; T. Mechichi, "Biodegradation of textile dyes by immobilized laccase from Coriolopsis gallica into Ca-alginate beads," Int. Biodeterior. Biodegradation, vol. 90, pp. 7178, May. 2014. http://dx.doi.org/10.1016/j.ibiod.2014.02.006

[77] A. Benhouria; A. Islam; H. Zaghouane-Boudiaf; M. Boutahala; B. H. Hameed, "Calcium alginate-bentoniteactivated carbon composite beads as highly effective adsorbent for methylene blue," Chem. Eng. J., vol. 270, pp. 621-630, Jun. 2015. http://dx.doi.org/10.1016/j.cej.2015.02.030

[78] L. Linhares; K. Alencar Silva; V. Pereira de Sousa; G. Cardoso Fontes-Sant'Ana; M. H. Rocha-Leão, "Blueberry Residue Encapsulation by Ionotropic Gelation," Plant Foods Hum. Nutr., vol. 73, pp. 278-286, Dec. 2018. https://doi.org/10.1007/s11130-018-0685-y

[79] N. Cujic; K. Trifkovic; B. Bugarski; S. Ibric; D. Pljevljakusic; K. Savikin, "Chokeberry (Aronia melanocarpa L.) extract loaded in alginate and alginate/inulin system," Ind. Crops Prod., vol. 86, pp. 120-131, Aug. 2016. https://doi.org/10.1016/j.indcrop.2016.03.045

[80] J. Guo; M. M. Giusti; G. Kaletunç, "Encapsulation of purple corn and blueberry extracts in Alginate-pectin hydrogel particles: Impact of processing and storage parameters on encapsulation efficiency," Food Res. Int., vol. 107, pp. 414-422, May. 2018. https://doi.org/10.1016/j.foodres.2018.02.035

[81] S. Ntohogian et al., "Chitosan Nanoparticles with Encapsulated Natural and UF-Purified Annatto and Saffron for the Preparation of UV Protective Cosmetic Emulsions,” Molecules, vol. 23, no. 9, Aug. 2018. https://doi.org/10.3390/molecules23092107

[82] X. Zhao; F. Qi; C. Yuan; W. Du; D. Liu, "Lipase-catalyzed process for biodiesel production: Enzyme immobilization, process simulation and optimization," Renew. Sustain. Energy Rev., vol. 44, pp. 182-197, Apr. 2015. https://doi.org/10.1016/j.rser.2014.12.021

[83] L. I. Rigoli Ferraz et al., "Application of home-made lipase in the production of geranyl propionate by esterification of geraniol and propionic acid in solvent-free system," Biocatal. Agric. Biotechnol., vol. 4, no. 1, pp. 44-48, Jan. 2015. https://doi.org/10.1016/j.bcab.2014.07.003

[84] L. Blemur; T. C. Le; L. Marcocci; P. Pietrangeli; M. A. Mateescu, "Carboxymethyl starch/alginate microspheres containing diamine oxidase for intestinal targeting," Biotechnol. Appl. Biochem., vol. 63, no. 3, pp. 344-353, May. 2015. https://doi.org/10.1002/bab.1369 